\title{
How does social media negatively affects the beginning of relationships?
}

Submitted by:

Sharon Aronowicz

Gal Gelbard

Friday September $2^{\text {th }} 2017$ 


\section{Introduction}

"Between 2005 and 2012 more than one third of couples who got married in the United States met through an online dating site. Online dating was the single biggest way people met their spouses. Bigger than work, friends, and school combined." Aziz Ansari, (2015).

Romantic relationships have drastically changed in today's world, affected by the role of social media and deeply changing the way we interact with each other. The way we approach one another might seems standard today, but importantly differs from what people did even just decades ago. The percentage of people meeting online keeps rising while traditional ways of finding your partner are constantly decreasing.

Online dating transformed our romantic lives; single people today have more romantic options than ever. The new trend of online romantic relationships leads to various questionings. Why do people decide to use social media to interact with each other rather than approaching someone in the street and invite him/her for diner? The issue of online self-presentation, the necessity of body language, and how does this change affect us in finding our life partner? It is this change we want to focus on, to try and find out how the rise of online dating drastically affected the art of finding a companion.

The aim is to intent to understand the different intentions behind social media when concerning romantic relationships. We can ask ourselves for instance, do people search today for long term connection when chatting on the net or maybe more alternative motives.

Of course, the rise of social media implies some new challenges and risks that are necessary to mention, we will mainly focus on how social media negatively

\section{affects the beginning of romantic relationships.}

Throughout the paper we will first focus on 5 focus points based on related work to the topic, in order to organize the information. The aim is to understand the connection between romantic relationships and social media, how do we present ourselves online, media richness, the Initiation of social ties on social media and finally analyzes the initiation of romantic ties on social media.

We will discuss prior research and go further into our research questioning focusing on the negative impact of this new kind of romantic relationship by 
conducting a survey and analyze how people perceive the role of social media in their own romantic life.

People have become so used to using social media that a more traditional way of dating is less and less considerable nowadays. Using social media to approach someone has become the new norm, and maybe the reason why we should be more alert and consider the negatives impacts it has on the initiation of romantic relationships. 


\section{Related Work}

This paper will present five focus points that contribute to the pressing questions regarding the presentation of individuals and dating in the online world. This section will analyze the following factors; connection between romantic relationships and social media, how we present ourselves online, media richness, initiating social ties on social media, and initiating romantic ties on social media. These topics will be examined through previous studies and texts from reliable authors and researchers and discussed further on in the paper.

\section{Connection between romantic relationships and social media}

Aziz Ansari and the American sociologist and New York University professor, Eric Klinenberg, together wrote a research book named Modern Romance where they explore the changes of romantic relationships in the past decades with the rise of social media. Today they state that "In 2014 the average American spent 444 minutes per day - nearly 7.5 hours - in front of a screen, be it a smartphone, tablet, television, or personal computer." And according to Ansari, "we're spending so much time with our digital devices because we've all developed our own personal 'phone worlds' and accompanying phone selves who live in this private space."

The role of social media became massive in today's search for a romantic partner and according to one of their research, between 2005 and 2012, one third of American married couples met online. Dating sites became one of the main ways for people to met their partner, more than through common friends or through work (Cacioppo, 2012). Those kinds of studies are consistent with studies conducted at the Stanford University by the sociologist Michael Rosenfeld. In one of his research, "How couples meet and stay together" where he used a study group representing all ages, he showed the rise of online dating, going from $5 \%$ to over $20 \%$ in the ways people meet their romantic partner today.

Aaron Smith, Senior Researcher, and Maeve Duggan Research Assistant conducted a research paper analyzing the connection between online dating and relationships. Indeed, social media allows people today to use much different application to reach to potential romantic relationships like tinder, a dating app or many of the famous social media apps. (Instagram, Facebook, Snapchat...) This 
approach via social media is called online dating. "One in ten Americans have used an online dating site or mobile dating app; $66 \%$ of these online daters have gone on a date with someone they met through a dating site or app, and $23 \%$ have met a spouse or long term partner through these sites. Public attitudes toward online dating have become more positive in recent years, but many users also report negative experiences." (Duggan \& Smith, 2013).

Since the invention of the Internet, it didn't take long for it's first touch to dating and relationships, starting in the mid-1990's with sites like Match.com. These kinds of dating apps offer different kind of forms of contact as they evolved until today according to weather or not matching algorithms are used or if simply people browse for interesting profile on their own.

Online dating offers appealing differences compared to traditional dating that seems to attract many. "The ability to search from a deep pool of potential partners outside of one's existing social networks; the ability to communicate online or via email prior to arranging for a face-to-face interaction; and matching algorithms that allow users to filter potential partners based on pre-existing criteria." (Duggan \& Smith, 2013). Two major changes allowed the world of online dating to find its place in today's customs; firstly, the apparition of smartphones drastically changed the notion of contact between people nowadays. "Today more than half of all American adults are smartphone owners, and dating-like many other aspects of modern life-is increasingly conducted on the go." (Duggan \& Smith, 2013).

Moreover, we can notice today a widespread adoption of social network sites, indeed more than providing dating apps, social media plays a role in connecting people between each other and therefore creating more opportunities for people to reach out to someone as well as with romantic intentions. "Today roughly three-quarters of online adults use sites such as Facebook and Twitter, and the impact of these online social networks on the dating process is potentially profound." (Duggan \& Smith, 2013).

Moreover, Duggan and Smith discuss the fact that online dating has become more accepted over time: $59 \%$ of Internet users agree with the statement "online dating is a good way to meet people." 
$53 \%$ of Internet users agree with the statement "online dating allows people to find a better match for themselves because they can get to know a lot more people" $21 \%$ of Internet users agree with the statement "people who use online dating sites are desperate."

\section{How do we present ourselves online?}

Catalina L. Toma, Jeffrey T. Hancock and Nicole B. Ellison conducted a study in 2008 to examine self-presentation in online dating profiles. They used eighty online daters and rated the accuracy of their online self-presentation. Research suggests that when individuals expect to meet a potential dating partner for the first time, they will alter their self-presentational behavior in accordance with the values desired by the prospective date (Rowatt, Cunningham, \& Druen, 1998). Even when interacting with strangers, individuals tend to engage in selfenhancement (Schlenker \& Pontari, 2000).

Online self-identity is a very relevant issue that will be further more discussed throughout the paper.

\section{Media richness}

Media richness is the ability of communication media to transmit rich messages. Richness is characterized as the amount of feedback, social cues, language variety, and personal focus that is conveyed to a communicative partner (Daft et al., 1987)

There are four main characteristics to define the richness of a media: Conveying multiple communication cues simultaneously such as facial expressions and voice intonations. Weather or not it enables immediate and rapid feedback on the message being conveyed. Its support for language variety and natural language, and lastly the personalization of messages and the personal focus.

Communication users will use the richest possible media available to them, which is usually face-to-face communication. Indeed, face-to-face communication is usually inevitable in romantic relationship but the rise of social media's connecting potential intimate partners have substantially increased in popularity in western cultures, and they report impressive success rates. Dynamic and sensory means of expression such as voice, facial expression or touch play an important role however online meetings have still proven to give positive result. More and 
more, people can engage long-term relationship through the help of social media. Moreover, most people will rather have a first contact through an online platform, before meeting someone face-to-face. We can access today to a more "complete" communication media, thereby intensifying the relationship and at the same time enriching the basis for mutual impression formation with preverbal and nonverbal cues. (Mierke et al,. 2016) Therefore arouse significance in the way we present ourselves online, as discussed previously.

\section{Initiating social ties on social media}

In Gilbert and Karahalios' paper, "Predicting tie strength with social media," they explore the differences of strong and weak ties within Facebook (for more recent application of this work see Hayat \& Hershkovitz, 2018; Hayat, Hershkovitz \& Azran, 2019) . By building a dataset of over 2,000 social media ties, their paper attempts to debunk the original idea that tie strength does not exist in social media, and rather, all relationships online are at an equal spectrum; it either exists or it doesn't.

Introduced by Mark Granovetter in 1973, tie strength is determined by how close you are to another individual. Strong ties represent trustworthy and strong friendships, while weak ties are merely acquaintances. Granovetter proposed four tie strength dimensions to analyze the intensity of a relationship, while others have expanded the list.

Gilbert and Karahalios expanded on the dimensions of tie strength, which are used to measure the strength of a relationship offline, such as intensity, intimacy, duration, and etc. The paper uses five questions based on these dimensions to analyze whether one can accurately predict the strength of friendships on Facebook; How strong is your relationship, how helpful is it looking for a job, how upset you would be if you were unfriended, how important is it is to bring a friend, and how comfortable one is asking for a loan.

Within the analyses, researchers can understand that Facebook filters one's ties strengths based on an algorithm, but one questions how accurate this algorithm is. Using these questions, researchers have found that characteristics such as age difference and number of overlapping networks have little to no effect on the strength of a relationship, while inbox threads negatively affect tie strength. "Common ground theory would suggest that strong ties can communicate very 
efficiently because of their shared understanding, perhaps manifesting as shorter Inbox threads."

It was shown that the contexts of close relationships are shifted in an online platform. According to one user, the unique bond she shared with her teacher was considered a close relationship, stating, "The professor still remembers my name, which for some of my "friends" on Facebook may not be true." Gilbert and Karahalios pointed out that many people would not typically consider someone who remembers their name as a strong tie, but there are certain relationships that challenge that criteria.

Additionally, another user determines the strength of some relationships based on a possible reconnection with the other. "Participants' responses often revealed the complexity of real-life relationships, both online and offline. One participant grounded her rating not in the present, but in the hope of reigniting a friendship:"

Ultimately, this study is not completely accurate due to the focus on Facebook specifically, and many questions are still present regarding the limit of tie strength predictability and unseen data; such as who friended whom. Nevertheless, this research revealed the complexity, importance and dimensions of tie strength on social media, notably focusing on the differing perceptions of tie strength online and offline.

\section{Initiating romantic ties on social media}

D. Chambers' paper "Social Media and Personal Relationships," details the potential anxieties and uncertainties that online dating generates. She describes the online dating world as spontaneous, casual, and informal, which oftentimes leads to uncertainties within the relationships themselves. "Participants of social media seem unable to agree on emergent dating rules and conventions, particularly among adolescents and especially when it comes to the end of a relationship. There are questions that are raised regarding management of intimacy in the digital age in terms of social media etiquette, agency, privacy and publicity, and vulnerability."

Additionally, further anxieties arise from both participants and nonparticipants of the online dating world. Non-participants feel excluded or left behind, while daters oftentimes have unrealistic and high expectations within their 
relationships, due to the continuous availability of the Internet. Furthermore, online daters have a difficult time labeling their relationship, leading to Walther's "Hyperpersonal Effect," which describes the increase in miscommunication and misinterpretation of the relationship due to the lack of physical cues.

A huge factor in the uncertainties within budding online relationships stem from Facebook; with actions such as "Facebook Stalking," a 'feedback loop' is perpetuated, which leads to continuous and addictive online stalking, prompting jealousy, and rage. Ultimately, the lack of face-to-face interaction can cause stress and misinterpretations within a relationship from beginning to end.

\section{Research Question and Hypothesis}

With the integration of technology in our everyday lives steadily increasing; we can wonder how this phenomena affects romantic relationships and dating. There are countless applications catered to individuals who seek potential partners, ranging from religious, sexual, and lifestyle preferences. With applications such as Tinder, Bumble, Jswipe and more, users can not only select their preferred application, but they can customize their settings to find their perfect match. According to a study, "One in ten Americans have used an online dating site or mobile dating app; $66 \%$ of these online daters have gone on a date with someone they met through a dating site or app, and $23 \%$ have met a spouse or long term partner through these sites." (Duggan \& Smith, 2013)

Although online dating sites are becoming progressively popular, the online world has also enabled individuals to form connections in unexpected places such as Instagram, Snapchat, and Facebook. This can lead to numerous individuals finding companionship and lifelong partners, but it can also lead to repercussions and doubts within a relationship and individually. The Digital Abuse Study reported, "Nearly 3 in 10 young people said that their partner has checked up on them online several times per day or read their text messages without permission."

The ability to meet countless individuals at once, both intentionally and unintentionally, can hugely impact the formation and ultimate success of potential relationships in the long run. Thus comes the will to deeper analyze the effect online tools have on relationships, ultimately posing the question; how does social media negatively effect the beginning of romantic relationships? 
Although our paper has presented both the positives and negatives of one's online persona and dating tendencies, the continuation of this paper will focus on clear obstacles to establishing and growing relationships due to presence and ambiguity of social media and online dating sites. This leads us to hypothesize that most relationships do not leave the initiation phase, thus deeming them unsuccessful. Our methodology will delve into how social media personally affects individuals, questioning their intentions and experiences with the online dating world.

\section{Methodology}

When initiating our research for this topic, we actively wanted to conduct a qualitative research methodology where we can acquire comparisons through questions that allowed the participants to share personal information, experiences, and opinions on our subject matter. Since we wanted simple, yet accurate representations for our data, we decided to create a questionnaire. This method allows us to gather data in an efficient manner, while still receiving a large amount of feedback from participants.

When developing a questionnaire, most questions had a yes or no answer, or a 1-5 scale that allowed participants to rate their answer in the simplest form. Our questionnaire was divided into three sections so we can accurately understand our participants, and our data can be analyzed through more than just the topic at hand. To elaborate, our questionnaire consisted of 20 questions total. The first three questions were catered towards understanding the individual, with questions regarding age, relationship status, and gender. The next section was gathering data on the opinions of our participants, specifically regarding their thoughts on online dating in general. Comprised of 12 questions, these questions included, "In your experience, how trustworthy are people you've met online from 1 to 5 with 5 the most trustworthy," and "Do you think there's more chance for you to meet your future partner online?"

The next section was focused specifically on social media, where we asked participants how a social media platform can affect relationships both online and offline. An example of questions include, "Do you often check someone's social media profile before going out with that person?" and "Has actions on social media 
affected the status of a potential relationship? (Comments, posts, and likes on a account(s))?" Additionally, we added a last section, which allowed participants to provide any extra comments, questions, concerns, or feedback that could help us with our research.

As shown, we believed it was important to have yes or no answers and scaled answers in order to provide organized and direct data to a topic that is otherwise mainly subjective.

When determining what our research topic would be, our main basis was to analyze a pattern we were observing within our companions and ourselves. This interest stemmed from our surroundings, thus we wanted our research to be catered towards young adults within our age range. Although our survey method was open to all ages, we believed it was important that our population was focused on age, which is why we asked participants to select their age range as our first question.

Additionally, since we believed our research would mainly attract the young adult age range (19-25) we believed most of our data would be submitted from this group, thus it was important to distinguish if this was truly the case or not. In our case, our results supported this speculation.

Regarding our sample, we wanted it to be as broad as possible so we can get the largest amount of responses. When posting our questionnaire, we posted it around Facebook, in groups such as Secret Tel Aviv, International Students in Israel, and our respective Facebook pages which opened us to youngsters all around the world. This meant we allowed people from all locations to participate, while still remaining focused on our interest in students and young adults around our age range.

Essentially, we believe our methodology and the distribution of our questionnaire is what allowed our results and ultimate conclusion to be complete and accurate. With questions that allowed each participant to provide personal details and opinions on their relationship and the online world, we were able to distinguish the positive and negative effects social media and online dating has had in their respective lives. 


\section{Results}

We presented our population sample with a survey to analyze their vision towards social media and the role it played in their romantic life. As expected, the answers came from mostly youngsters between 19 and 25 years old, with still 13\% older but only $2 \%$ younger.

Out of all the people the survey was shared to, $70 \%$ of the answers came from women against $30 \%$ from men. There are no clear distinctions between men or women's behavior in our research so it won't affect our results.

Our first question asked our audience if they thought online dating was a good way to meet people ( $77 \%$ said yes) and $80 \%$ believed it does not mean you are desperate. Those first two questions were aimed at giving us a first glance to how people perceive the role of social media in online dating.

However, when we asked if they agree or disagree with this statement: "Online dating keeps people from settling down because they always have options for people to date." the gap was tighter between yes and no, still more no, which proves a certain positive vision of social media, but still some uncertainty. Trust is something to consider when online dating, it is important to understand that the interaction is with someone we never met before. In general, people are likely to be pretty honest online; most online deception does not involve the creation of false identities. But we need to consider the fact that it is indeed much easier to lie online than offline, particularly about your physical appearance for example. However, when asking people their experience on how trustworthy are people they have met online from 1 to 5 with 5 the most trustworthy this were the results:

The majority answered 3, which shows a certain uncertainty concerning the question but still leaning towards the trustworthiest. 
The role of social media in initiating romantic social ties was asked with the following question: Do you feel like chatting with someone online is necessary before meeting them face to face?

$60 \%$ of our population answered yes, showing how nowadays people are more used to chat through social media, getting to know the online version of the other before accepting to go out with them. Interestingly when we purposely followed with asking how much do they base their judgment on someone according to his profile most answers fell on 4 out of 5 the most influenced by the online profile of a person and $20 \%$ on the 5 .

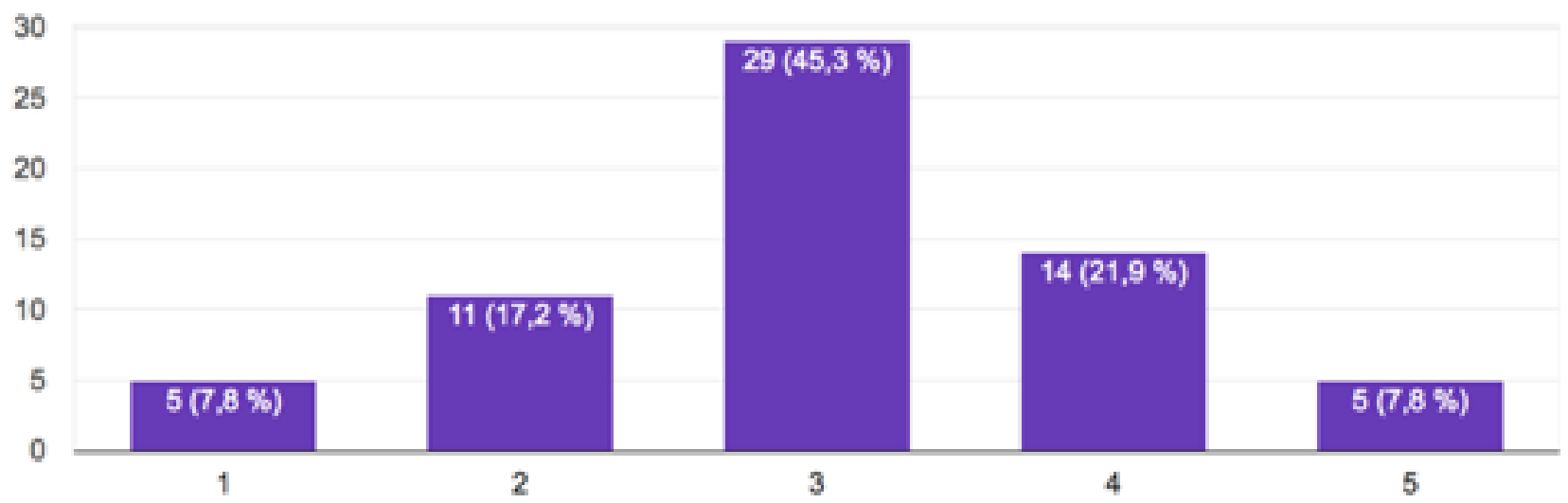

The question that brought the most confusion in answers was probably concerning what intentions in terms of relationship where people searching when looking for a companion online.

We asked them to rate out of 5 how serious they were when looking for a partner with 5 the most serious relationship possible. It seems like most people awe for a serious relationship with the hope to find their soul mate, but following very title with 3 and 4 showing very mixed results and opinions. Indeed the Internet provides so many choices that some have testified being hard to settle on one person (Love me Tinder, 2017). 

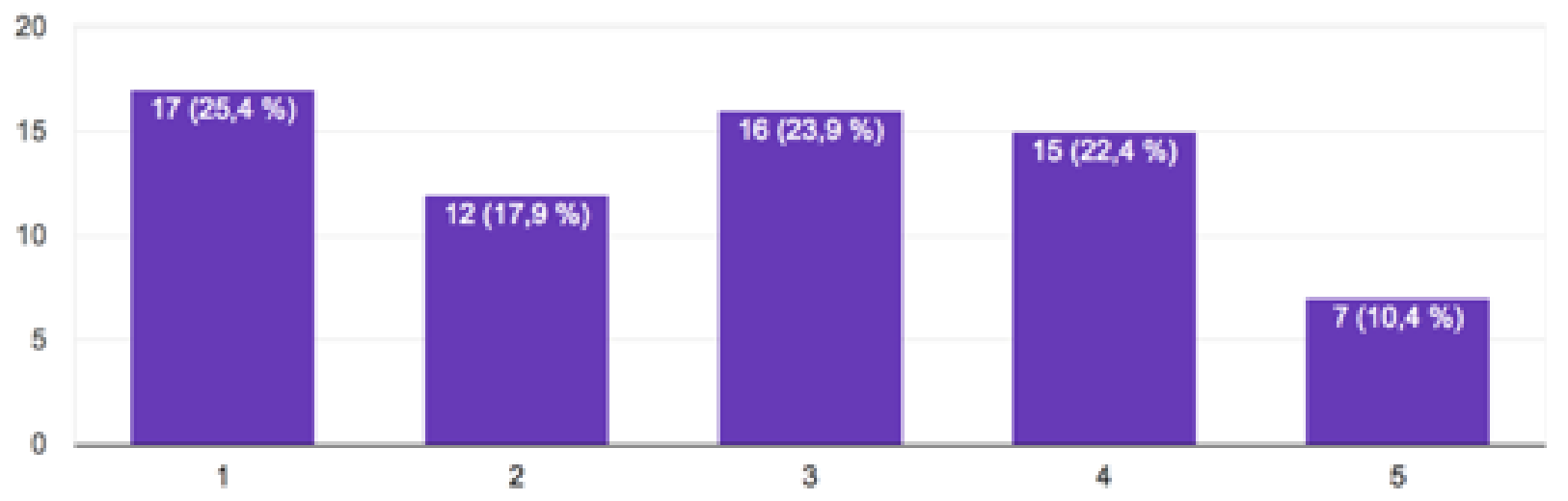

When creating a profile on dating apps, chatting on social media to seduce someone, $20 \%$ admit already lying about themselves to enhance your selfpresentation.

Even though social media took a huge role in today's romantic games, $70 \%$ of people still think online doesn't necessarily provide more chances of finding their future partner.

One of the person participating in the survey commented in the opinion rubric: " $80 \%$ of our communication comes from our body language. Very important to consider while meeting a new person but through social media we can't see it." $65 \%$ say they have never used social media to start romantic relationships, but $70 \%$ have been contacted through social media to initiate a romantic relationship. It is important to note that $70 \%$ of answers come from women that are usually more solicited online.

Facebook still is the number one social media platform people would consider best to contact someone they are interested in (73\%), followed by Instagram and then Snapchat, leaving aside dating applications. Through these kinds of social media, $30 \%$ developed a romantic relationship unexpectedly. Infidelity, also mentioned many times in Love me Tinder (2017) "So many different options right at your fingertips" brings us to the following question: Does social media influence you towards infidelity? 


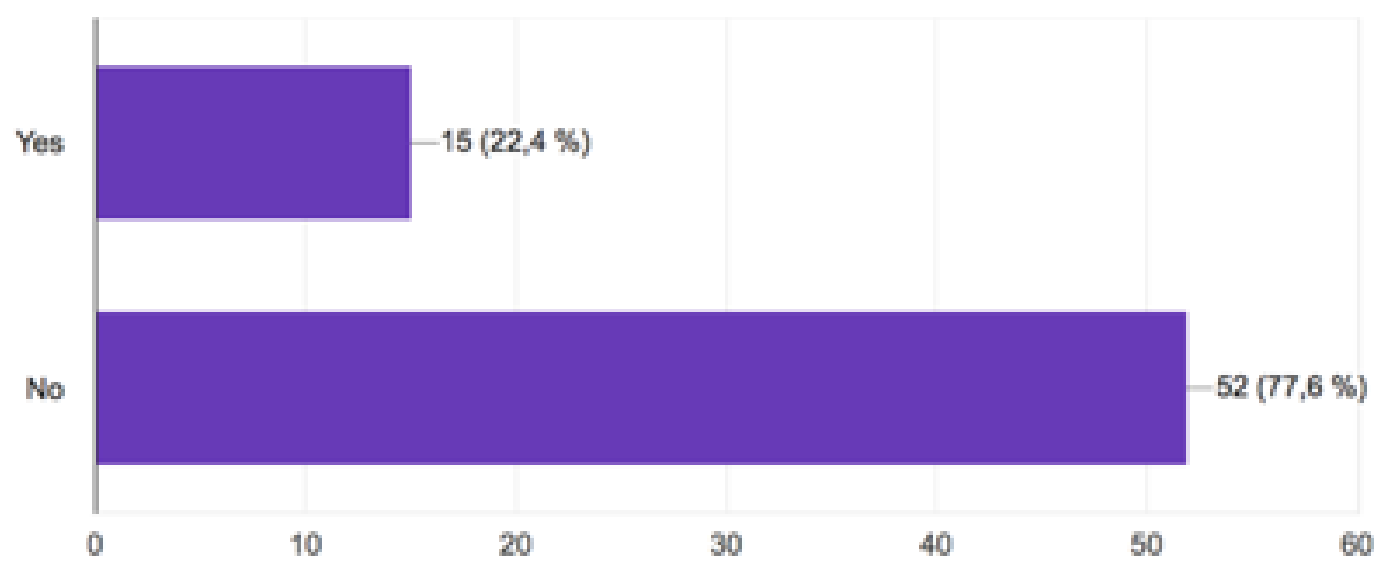

According to our survey, most people seem to believe they can stay faithful, but $22 \%$ does say it has an impact on the fidelity.

But when going more in-depth in the question and asking specifically if some actions on social media affected the status of a potential relationship, such as suspicious comments, posts, and the classic likes on a account/picture? Almost half of the people participating in the survey answered positive.

Finally, we wanted to prove an irrational behavior by questioning if people check someone's social media profile before going out with that person. As expected, most people do (70\%) but then when looking at the next results, again $70 \%$ of participants will affirm someone's social media profile cannot accurately represent the person he/she is in real life. 


\section{Discussion}

We saw previously that $70 \%$ of people still think online doesn't necessarily provide more chances of finding their future partner. A rather contradictory statement when looking at the role of social media in today's romantic games. We can ask ourselves if people will still have more trust towards someone they met in "real" life, able to apply their own judgment. Or maybe because the people they meet online are not the ones they consider as a future partners but maybe more towards a casual relationship.

One of our participants thought it was important to add a comment on the importance of our body language when interacting with someone, which is mostly left out in the online dating world. It seems like body language is still very an essential ingredient of attraction, the smile, the touch and the eye contact are necessary.

How does $70 \%$ of participants affirm that someone's social media profile cannot accurately represent the person he/she is in real life but then still systematically check their online information before meeting them?

Some first questionable conclusions can be drawn from this. In most cases people decide how they are represented on social media. They have direct control about the gatherable information concerning them. This way someone can get a first impression about the person they might go out with. Although it is a controlled impression some basic values can gleam through. Additionally one could also already get informed about some mutual interests or gather possible conversation topics. So even though most people do not feel like getting a an accurate 
personality representation they might try to get a first glance, so they might not head towards a total failure.

When $70 \%$ of participants admit to have been contacted through social media to initiate a romantic relationship it is important to remember that $70 \%$ of answers came from women. Women are usually much more solicited online. Indeed in his book Dataclysm, OkCupid founder Christian Rudder illustrates this difference with the following graph of user data from OkCupid. This is a chart of messages received per day plotted against attractiveness based on user ratings.

\section{MESSAGES PER DAY ON OKCUPID BY}

\section{ATTRACTIVENESS}

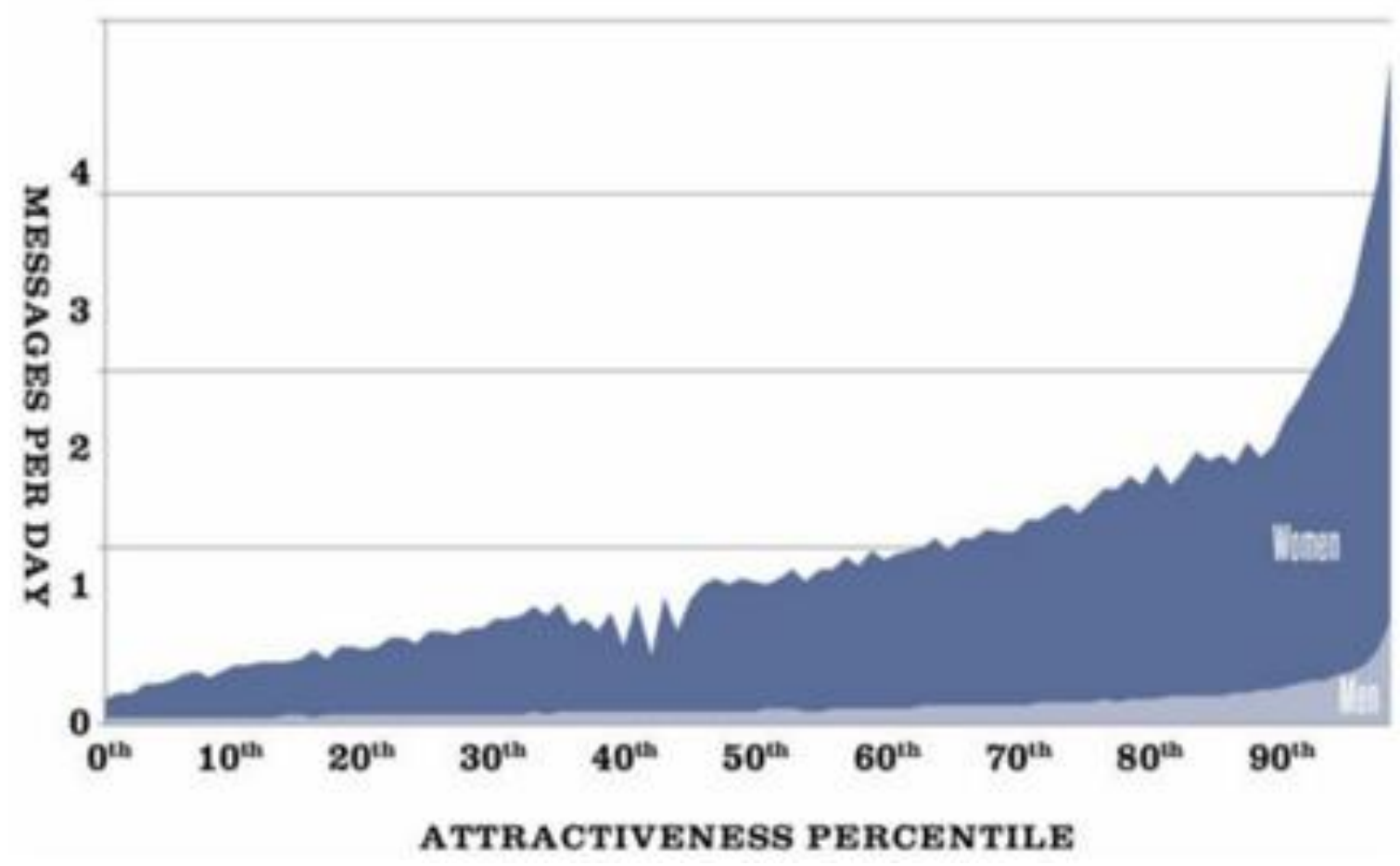

Therefore we can see that women are much more solicited then men, creating areal imbalance in the dating game, followed by frustration, and pushing people to judge others on superficial characteristics.

\section{Love Me Tinder, 2017}

We decided to add to the discussion the case of Love Me Tinder. This episode is part of an American documentary series meant to explore and depict the threats of love and sex in the digital age. The Love Me Tinder episode follows 
James Rhine and his addiction to dating application and the way it impacts is romantic life. He explains how all those "different option at your fingertips" makes commitment very difficult in a relationship as discussed before. Dating apps offers an easy way to get girls, a new approach that offers a solution to those who had difficulties approaching someone in real life. However, in the short documentary, we can understand that having all those possibilities for casual relationships have some very negative aspects on the beginning of romantic relationship. The main character testifies that he feels he can always find someone better because there are "too" many choices" and therefore, it is hard for him to settle on one person, the case of 1 in 4 person using dating apps according to the documentary. Which usually is followed by the "Ghosting phenomenon" making it much harder to find someone. Ghosting is defined as abruptly ending a personal relationship without giving the other person reason or explanation, usually because there are none, and cutting off all communication. A disappearing act, to easily move on the next swipe on your phone. It's like breaking up with someone without telling them you wanted to break up, so you just disappear.

1 in 5 people using dating apps have been ghosted, and 1 in 3 people using dating apps admit having ghosted someone else.

In the documentary, we listen to a young woman opening up to how she feels after someone "ghosted" her, her obsession when checking his different social media accounts and her pain when she explains how it affected her.

Rhodes admit that even when he likes a person, he might unconsciously find an excuse to sabotage the relationship because he knows it is so easy for him to find someone else on dating apps, and probably because he misses the feeling and excitement of swiping on attractive potential partners.

"Dating is a jungle" comments one girl, people don't slow down anymore, look for the fun and excitement of it and won't realize the consequences of their actions.

Experts say those same social networks have made it easier for people who are inclined to cheat on their significant other to do so with partners both familiar and previously unknown. "Social media seems to have added fuel to the fire of infidelity," says Joyce Marter, a licensed psychotherapist and the CEO of Chicago-based counseling practice Urban Balance. "Former flames are just a click away. Appropriate relationship boundaries can become blurry. For example, when does casual messaging cross the line into an emotional affair? "For people who 
are morally willing to and motivated to, social media offers an unprecedented opportunity to engage in unfaithful behavior," adds Benjamin Karney, a professor of social psychology at the University of California at Los Angeles who has extensively studied interpersonal relationships and marriage. "You don't even have to find somebody who is in your neighborhood. You can flirt and exchange sexual communication with anyone who is willing to do it on planet Earth who is holding a smartphone."

Your online profile will define the impression formation people will get from you. Let's take a look at frequent characteristics people include in their profile, we have basic info, their looks, obviously determining in a profile. The different areas of interest in order find common points with your future partner. And many different details such as hobbies, desires, hopes, aspirations with regard to the relationship. For some it will be important to indicate religious beliefs, political orientation. We have application such as Jdate "Find your special Jewish someone" which works very well in the Jewish community. People feel the need to be part of a group, and therefore will be more attracted to similar people.

Online dating challenges people to sell themselves, to compete with the millions of others in the same quest to find a partner. Therefore people indicate mostly their good traits and neglect any negative characteristic. There is this need to feel positively, and thus, some exaggerate and present a "better self". Most do not really lie but still will omit to say some characteristics of their own and often, people edit and rewrite their profile.

Because the interaction is online, there is a lot of room for people to consider persuasive strategies to sell themselves, and choose from the market that's out there. In other words, more possibility to persuade and influence people. But why this urges to "sell" ourselves? Two perspective try to explain this phenomena of online dating.

The social exchange perspective explains that people today seek more rewards than costs in relationships. Therefore, the more rewards we have, the higher chances we will have to have a relationship with someone.

The evolutionary perspective demonstrates that men seek certain traits in their female partner (i.e. be fertile for reproducing offspring) and women seek specific 
characteristics in their male partner (i.e. signs of strength showing they are able to protect and provide)

We can then assume that the reason female dating profiles look different than male profile may be due to this evolutionary explanation?

\section{Conclusion}

Through extensive data, both from previous research and our questionnaire, our conclusion has varied throughout different elements of our initial research question. The importance of analyzing both the positive and negative effects of this new-age tool of forming and keeping relationships have been brought to light within this paper. It has provided a platform for users to have a deeper understanding of the range of elements within using social media, and to delve into the potential side effects and unexpected outcomes this platform can bestow.

Through delving into the online dating world, and ultimately deeming it to have a negative impact on the formation of relationships, our methodology and results within our research has both supported and refuted this claim. To reiterate, our research has proved that although participants believe social media allows one to manipulate their image and not accurately represent them, it is still a basis of judging a potential partner before meeting them.

Ultimately, although social media makes it more difficult to fully assess a potential partner or situation, it is still shown to accelerate and enable encounters and conversations in ways that are more comfortable and casual. Thus, forming an easygoing and informal relationships are more successful through an online platform, whereas few users are looking for serious and committed relationships. 


\section{References}

Al-Yagon, M., Mikulincer, M. (2004) The Meditational Role of Attachment-Based Factors. The Journal of Special Education, 38(2), 111- 124.

Ansari, A., Klinenberg, E. (2015). Modern Romance. New York: Penguin Press.

Brodwin, E. (2016). Here's how American couples actually meet their significant others. Business Insider. From http://www.businessinsider.com/mostamerican-couples-meet-online-2016-9

Chambers, D. (2013). Social Media and Personal Relationships: Online Intimacies and Networked Friendship, University of Newcastle, UK.

Duggan, S., Smith, A., et. al. (2013). Teens, Social Media, and Privacy. The Berkman Center for Internet and Society and Harvard University.

Eli J, Eastwick, P., Karney, B. et. al. (2012). Online Dating: A Critical Analysis From the Perspective of Psychological Science. Psychological Science in the Public Interest, 13 (1), 3-66. Northwestern University, Texas A\&M University, University of California, Los Angeles, University of Rochester, Illinois State University.

Ellison, N., Heino, R., Gibbs, J. (2006). Managing Impressions Online: SelfPresentation Processes in the Online Dating Environment. Journal of Computer-Mediated Communication, 11 (2), 415-441.

Fellizar, K. (2015). Online Dating Is The Second Most Popular Way To Meet Someone, Says New Study, And More Things To Know About Dating In The Digital Age. Bustle. From https://www.bustle.com/articles/105558-onlinedating-is-the-second-most-popular-way-to-meet-someone-says-new-studyand-more 
Gilbert, E. Karahalios, K. (2009). Predicting Tie Strength With Social Media. University of Illinois at Urbana-Champaign.

Hayat, T., \& Hershkovitz, A. (2018). The role social cues play in mediating the effect of eWOM over purchasing intentions. Journal of Customer Behavior. 17 (3), 173-187.

Hayat, T., Hershkovitz, A., \& Samuel-Azran, T. (2019). The independent reinforcement effect: The role diverse social ties play in the credibility assessment process. Public Understanding of Science, 28(2), 201-217.

Hoffman, R. (2015). How The Ghosting Phenomenon Is Making It Impossible To Date. Elite Daily. From http://elitedaily.com/dating/ghosting-impactsdating/1027661/

Mierke, K., Aretz, W., Nowack, A., Wilmsem, R., \& Heinemann, T. (2016). Impression Formation in Online-Dating-Situations: Effects of media richness and physical attractiveness information.

Rohamnpton, J. (2017). Millennials, Here's How Social Media Impacts Your Relationships. Forbes from https://www.forbes.com/sites/jimmyrohampton/2017/05/03/millennials-hereshow-social-media-impacts-your-relationships/\#6db5c8717922.

Toma, C., Hancock, J., Ellison, N. (2008). Separating Fact From Fiction: An Examination of Deceptive Self-Presentation in Online Dating Profiles, 34 (8), 1023-1036. Cornell University, Michigan State University.

Walther, J.B., (1996).Computer-Mediated Communication: Impersonal, Interpersonal, and Hyperpersonal Interaction, 23 (1), 3-43. 
